\title{
CS Research Suare \\ SARS-CoV-2 air and surface contamination on a COVID-19 ward and at home
}

Lotta-Maria A. H. Oksanen ( $\square$ lotta.oksanen@helsinki.fi )

University of Helsinki

Jenni Virtanen

University of Helsinki

Enni Sanmark

Helsinki University Hospital

Noora Rantanen

Helsinki University Hospital

Vinaya Venkat

University of Helsinki

Svetlana Sofieva

University of Helsinki

Kirsi Aaltonen

University of Helsinki

Ilkka Kivistö

University of Helsinki

Julija Svirskaite

University of Helsinki

Aurora Díaz Pérez

University of Helsinki

Joel Kuula

Finnish Meteorological Institute

Lev Levanov

University of Helsinki

Antti-Pekka Hyvärinen

Finnish Meteorological Institute

Leena Maunula

University of Helsinki

Nina Atanasova

University of Helsinki

\section{Sirpa Laitinen}

Finnish Institute of Occupational Health

Veli-Jukka Anttila

Helsinki University Hospital

Lasse Lehtonen

Helsinki University Hospital

Maija Lappalainen

Helsinki University Hospital 


\section{Ahmed Geneid}

Helsinki University Hospital

\section{Tarja Sironen}

University of Helsinki

\section{Research Article}

Keywords:

Posted Date: December 6th, 2021

DOI: https://doi.org/10.21203/rs.3.rs-1002547/v2

License: 우 (i) This work is licensed under a Creative Commons Attribution 4.0 International License. Read Full License 


\section{Abstract}

SARS-CoV-2 has been detected both in air and on surfaces, but questions remain about the patient-specific and environmental factors affecting virus transmission to the environment. Additionally, more detailed information on viral findings in air is needed. This cross-sectional study presents results from 259 air and 252 surface samples from the surroundings of 23 hospitalized and eight home-treated COVID-19 patients between July 2020 and March 2021 and compares the results between the measured environments and patient factors. The proportions of PCR-positive air and surface samples showed statistical similarity in hospital and in the home. In four cases, positive environmental samples were detected even after the patients had developed a neutralizing IgG response. SARS-CoV-2 RNA was detected in the following particle sizes: 0.65-4.7 $\mu \mathrm{m},>7 \mu \mathrm{m},>10 \mu \mathrm{m}$, and $<100 \mu \mathrm{m}$. Appropriate infection control against airborne and surface transmission routes is needed in both environments, even after antibody production has begun.

\section{Introduction}

Increasing scientific evidence indicates the dominance of short- and long-term airborne transmission of SARS-CoV-2 ${ }^{1-6}$, and discussion on precautions for hospital and home environments has been intense. In a study that aerosolized SARSCoV-2 under laboratory conditions, aerosols' infectivity retained for up to $16 \mathrm{~h}^{7}$, while another study estimated the halflife in aerosols to be approximately 1.1 to 1.2 hours $(95 \% \mathrm{Cl} 0.64 \text { to } 2.64)^{8}$. Outside of the laboratory, signs of viable SARS-CoV-2 in the air have been detected, and virus was recently also cultured from exhaled air ${ }^{9-11}$. In hospitals, PCRbased studies have detected SARS-CoV-2 RNA in room air ${ }^{12-14}$, as well as from air conditioning filters located over $50 \mathrm{~m}$ from the patient room ${ }^{15}$. However, these studies used long collection times or high flow rates, generating large sample volumes mainly from small spaces, and thus questions remain about the risk of infection during shorter meetings or in rooms with a larger air space, and whether the findings would be similar in the home environment.

According to laboratory findings, the stability of SARS-CoV-2 on surfaces varies depending on the surface type and environmental conditions ${ }^{8,16-19}$. However, its ability to sustain infectivity on surfaces in real environments is largely unknown ${ }^{20}$. SARS-CoV-2 RNA has been found, for example, on high-touch surfaces, floors, and toilets ${ }^{13,14,21}$, but no study has yet been able to culture SARS-CoV-2 from surfaces in real environments. The effect of age and neutralizing antibodies (NAbs) on the spread of SARS-CoV-2 has been speculated ${ }^{22-24}$, but there is a lack of clear evidence for the role of patient-related factors.

This study sought to increase knowledge of SARS-CoV-2 transmission in different environments by analyzing air, surface, and patient samples from a COVID-19 cohort ward in Helsinki University Hospital (HUS), Finland, and from patients' homes. The aims were to determine whether SARS-CoV-2 RNA or viable virus could be found in the home and hospital environments, and which patient- and environment-related factors affect the risk of environmental contamination. A team consisting of researchers from HUS, the University of Helsinki, the Finnish Meteorological Institute, and the Finnish Institute of Occupational Health was established to enable a multidisciplinary approach to the above research questions.

\section{Results}

\section{Patient characteristics}

We performed 23 sample collections in HUS and 7 collections in patients' homes in the Uusimaa region, Finland, between July 2020 and March 2021. Collections included 31 index patients (1-2 per collection), 21 of whom were treated on a COVID-19 cohort ward in a large patient hall, one in a single-patient room, one in the intensive care unit 
(ICU), and eight patients treated in their homes (Fig. 1). Patient characteristics, including symptoms and laboratory results, are summarized in Table 1 (see Tables S1 and S2 for details of the patients and statistical tests used throughout the manuscript).

Table 1

Characteristics of hospital-treated and home-treated index patients and statistical differences between the two groups.

\begin{tabular}{|c|c|c|c|c|}
\hline & Hospital (n = 23) & Home $^{a}(n=8)$ & Total $(\mathbf{N}=31)$ & $\mathbf{p}$ \\
\hline Gender (\% of males) & 56.5 & 50.0 & 54.8 & $1.000^{\mathrm{g}}$ \\
\hline Mean age (years) & $60.4[19.45]$ & $26.0[7.21]$ & $51.55[22.90]$ & $<0.001^{f}$ \\
\hline Mean time from the onset of symptoms (days) & $7.6[3.10]$ & $4.5[1.41]$ & $6.81[3.07]$ & $<0.001^{\mathrm{h}}$ \\
\hline Mean time from the last positive PCR (days) & $1.8[1.98]$ & $3.5[2.54]$ & $3.03[2.50]$ & $0.145^{f}$ \\
\hline Fever on collection day (\%) & 69.6 & 25.0 & 58.1 & $0.043^{g}$ \\
\hline Respiratory symptoms ${ }^{\mathrm{b}}(\%)$ & 95.7 & 67.5 & 87.1 & $0.043^{\mathrm{g}}$ \\
\hline Gastrointestinal symptoms ${ }^{\mathrm{c}}(\%)$ & 47.8 & 25.0 & 41.9 & $0.412^{\mathrm{g}}$ \\
\hline Mean C-reactive protein level ${ }^{d}$ & $79.1 .4[68.34]$ & & & \\
\hline Mean ferritin level in plasma & $457.2[347.88]$ & & & \\
\hline Abnormal leucocytes (\%) & 30.4 & & & \\
\hline Low lymphocytes (\%) & 73.9 & & & \\
\hline Low eosinophiles (\%) & 65.2 & & & \\
\hline High alkaline phosphatase (\%) & 14.3 & & & \\
\hline High alanine aminotransferase (\%) & 43.5 & & & \\
\hline Mean D-dimer value & $2.2[6.91]$ & & & \\
\hline Mean fibrinogen value & $4.7[1.34]$ & & & \\
\hline Low SpO2 level (\%) & 65.2 & & & \\
\hline High respiration rate (\%) & 78.3 & & & \\
\hline \multicolumn{5}{|l|}{ Standard deviations are reported in brackets [ ] } \\
\hline \multicolumn{5}{|c|}{ a Laboratory results of home-treated patients were not available } \\
\hline \multicolumn{5}{|c|}{${ }^{b}$ Cough, hoarseness, sore throat, or shortness of breath } \\
\hline \multicolumn{5}{|l|}{${ }^{\mathrm{c}}$ Diarrhea, vomiting, stomach pain, or nausea } \\
\hline${ }^{\mathrm{d}}$ Results below the detection limit of 4.0 were & o 2.0 for calcula & & & \\
\hline
\end{tabular}

e Results below the detection limit of 0.3 were set to 0.2 for calculations 
${ }^{\mathrm{f}}$ Independent-Samples Mann-Whitney U test

${ }^{g}$ Fisher-Freeman-Halton Exact Test

h Independent-Samples T-test

\section{SARS-CoV-2 RNA in air}

Overall, 259 air samples were obtained from 29 air collections (Table S3). The samples were divided into actively and passively collected samples based on the collection method (see methods and the results below for details). In total, 33 (12.7\%) air samples from $12(41.4 \%)$ collections were PCR positive. The rate of positive home collections was $57.1 \%$ and hospital collections $36.3 \%$ ( $p=0.403)$. All air samples were cultured, but no viable viruses were observed. The protocols and tests used to optimize the culturing protocol are described in the supplementary methods. Although five hospitalized index patients used nasal canula oxygen or an oxygen mask during collection, which are considered as aerosol generating procedures, no positive air results were found during these collections.

\section{Active air sampling}

Altogether, 154/259 (59.4\%) air samples were collected with five different active air samplers, comprising 1) three simultaneous Andersen six-stage cascade impactors (Andersen) with different sampling times, 2) a BioSpot 300p bioaerosol sampler (BioSpot), 3) a Button sampler (Button), 4) a Dekati PM10 cascade impactor (Dekati), or 5) a Dekati eFilter (eFilter). The time from the start of symptoms to air collection varied from 3-12 days. Positive samples were observed in 2/11 (18.2\%) collections with the Dekati, 0/9 (0.0\%) with the Biospot, 2/9 (22.2\%) with the Button, 2/5 (40.0\%) with the Andersen, and 0/2 (0.0\%) with the eFilter (Table S4, results from home and hospital collections have been combined, as there was no statistically significant difference between the positivity rates for the collections). SARS-CoV-2 RNA was found from particles in the size ranges $0.65-4.7 \mu \mathrm{m}$ and $>7 \mu \mathrm{m}$ in Andersen collectors, $>10 \mu \mathrm{m}$ and $<2.5 \mu \mathrm{m}$ in Dekati samplers and $<100 \mu \mathrm{m}$ in Button samplers (Tables 2 and S3). On-line particle concentrations measured with the eFilter on the COVID-19 ward were in the range of $534-6608 \mathrm{~cm}^{-3}\left(3380 \pm 2320 \mathrm{~cm}^{-3}\right)$, and no clear particle emission events were observed. 
Table 2

Characteristics of PCR-positive air samples with active air sampling

\begin{tabular}{|c|c|c|c|c|c|c|}
\hline Place & Patient & $\begin{array}{l}\text { Days from the onset of } \\
\text { symptoms }\end{array}$ & Sampler & $\begin{array}{l}\text { Sampling } \\
\text { time (min) }\end{array}$ & $\begin{array}{l}\text { Collected air } \\
\text { volume (I) }\end{array}$ & $\begin{array}{l}\text { Size fraction } \\
(\mu \mathrm{m})\end{array}$ \\
\hline \multirow{18}{*}{$\begin{array}{l}\text { Hospital, } \\
\text { cohort }\end{array}$} & P2 & 10 & Dekati & 195 & 3900 & $>10$ \\
\hline & P26 & 14 & Dekati & 180 & 3600 & $<1.0$ \\
\hline & P40 & 4 & Button & 18 & 72 & $\leq 100$ \\
\hline & \multirow[t]{11}{*}{ P49 } & \multirow[t]{11}{*}{7} & \multirow{2}{*}{$\begin{array}{l}\text { Andersen } \\
1\end{array}$} & 10 & 283 & $1.1-2.1$ \\
\hline & & & & 10 & 283 & $0.65-1.1$ \\
\hline & & & \multirow{5}{*}{$\begin{array}{l}\text { Andersen } \\
2\end{array}$} & 20 & 566 & $>7$ \\
\hline & & & & 20 & 566 & $3.3-4.7$ \\
\hline & & & & 20 & 566 & $2.1-3.3$ \\
\hline & & & & 20 & 566 & $1.1-2.1$ \\
\hline & & & & 20 & 566 & $0.65-1.1$ \\
\hline & & & \multirow{4}{*}{$\begin{array}{l}\text { Andersen } \\
3\end{array}$} & 30 & 849 & $>7$ \\
\hline & & & & 30 & 849 & $3.3-4.7$ \\
\hline & & & & 30 & 849 & $2.1-3.3$ \\
\hline & & & & 30 & 849 & $0.65-1.1$ \\
\hline & \multirow[t]{4}{*}{ P54 } & \multirow[t]{4}{*}{7} & \multirow{2}{*}{$\begin{array}{l}\text { Andersen } \\
1\end{array}$} & 10 & 283 & $3.3-4.7$ \\
\hline & & & & 10 & 283 & $1.1-2.1$ \\
\hline & & & $\begin{array}{l}\text { Andersen } \\
2\end{array}$ & 20 & 566 & $2.1-3.3$ \\
\hline & & & $\begin{array}{l}\text { Andersen } \\
3\end{array}$ & 30 & 849 & $3.3-4.7$ \\
\hline \multirow[t]{2}{*}{ Home } & P10 & 2 & Dekati & 180 & 3600 & $1.0-2.5$ \\
\hline & P42 & 5 & Button & 21 & 84 & $\leq 100$ \\
\hline
\end{tabular}

During each Andersen collection, three Andersen samplers were used simultaneously.

The Button sampler is limited to particles smaller than $100 \mu \mathrm{m}$, but does not differentiate the sizes inside this range. Similarly, the largest particle stages in Dekati $(>10 \mu \mathrm{m})$ and Andersen samplers $(>7 \mu \mathrm{m})$ do not limit the upper size range.

\section{Passive air sampling}

A total of 91 passive air samples (14 collections) were collected by deposition on open cell culture plates. The mean collection time was 0.69 hours (range $0.3-3.0 \mathrm{~h}, \mathrm{SD} 0.51$ ) and the mean distance from the patient was $0.94 \mathrm{~m}$ (range 0.2-5.0 m, SD 0.84). Sampling points differed between home and hospital collections $(p=0.001)$, but distances from the patient were similar $(p=0.398)$. In total, 12 deposition samples $(11.5 \%)$ in $8(57.1 \%)$ collections were positive for SARS-CoV-2 RNA (Table 3). There was no statistically significant difference in the proportions of PCR-positive samples 
$(p=0.333)$ or collections $(p=1.000)$ between home and hospital. Only one sample, A77 (table, $0.2 \mathrm{~m}$ from the patient), was successfully quantified with qPCR, with a result of $3.56 \times 10^{3} \mathrm{copies} / \mathrm{ml}$.

Thirteen respiratory samples (coughing, breathing, talking for 2 minutes in front of an open cell culture plate, or spitting once onto an open cell culture plate) were collected from seven patients with a mean symptom day of 7.8 (range 5-8, SD 2.17). Out of all the respiratory samples, only one of the spit samples was PCR positive (Table S3).

Table 3

PCR-positive passive air sampling (deposition) results based on the sampling place and distance from the patient.

\begin{tabular}{|c|c|c|c|c|c|c|c|c|c|}
\hline & \multicolumn{3}{|l|}{ Total } & \multicolumn{3}{|c|}{ Hospital } & \multicolumn{3}{|c|}{ Home } \\
\hline & $\mathrm{N}$ & $\%$ & $\begin{array}{l}95 \% \\
\mathrm{Cl}\end{array}$ & $\mathrm{N}$ & $\%$ & $\begin{array}{l}95 \% \\
\mathrm{Cl}\end{array}$ & $\mathrm{N}$ & $\%$ & $\begin{array}{l}95 \% \\
\mathrm{Cl}\end{array}$ \\
\hline Window sill & $2 / 8$ & 25.0 & $\begin{array}{l}5.6- \\
59.2\end{array}$ & $0 / 4$ & 0.0 & NA & $2 / 4$ & 50.0 & $\begin{array}{l}12.3- \\
87.7\end{array}$ \\
\hline Table & $5 / 42$ & 11.9 & $\begin{array}{l}4.7- \\
24.1\end{array}$ & $3 / 21$ & 14.3 & $\begin{array}{l}4.2- \\
33.4\end{array}$ & $2 / 21$ & 9.5 & $\begin{array}{l}2.0- \\
27.2\end{array}$ \\
\hline Behind the patient & $1 / 7$ & 14.3 & $\begin{array}{l}1.6- \\
50.1\end{array}$ & $0 / 3$ & 0.0 & NA & $1 / 4$ & 25.0 & $2.8-$ \\
\hline Floor & $3 / 29$ & 10.3 & $\begin{array}{l}3.0- \\
25.1\end{array}$ & $2 / 26$ & 7.7 & $\begin{array}{l}1.6- \\
22.5\end{array}$ & $1 / 3$ & 33.3 & $\begin{array}{l}3.9- \\
82.3\end{array}$ \\
\hline $\begin{array}{l}\text { In front of the face during talking, } \\
\text { coughing, spitting, or breathing }\end{array}$ & $1 / 13$ & 7.7 & $\begin{array}{l}0.8- \\
30.7\end{array}$ & $1 / 11$ & 9.1 & $\begin{array}{l}1.0- \\
35.3\end{array}$ & $0 / 2$ & 0.0 & NA \\
\hline Self & $0 / 1$ & 0.0 & NA & NA & NA & NA & $0 / 1$ & 0.0 & NA \\
\hline Another room with closed door & $0 / 4$ & 0.0 & NA & $0 / 3$ & 0.0 & NA & $0 / 1$ & 0.0 & NA \\
\hline$<0.5 \mathrm{~m}$ & $7 / 43$ & 16.3 & $\begin{array}{l}7.6- \\
29.3\end{array}$ & $3 / 28$ & 10.7 & $\begin{array}{l}3.1- \\
25.9\end{array}$ & $4 / 15$ & 26.7 & $\begin{array}{l}9.7- \\
51.7\end{array}$ \\
\hline $0.5-1 \mathrm{~m}$ & $2 / 20$ & 10.0 & $\begin{array}{l}2.1- \\
28.4\end{array}$ & $2 / 14$ & 14.3 & $\begin{array}{l}3.1- \\
38.5\end{array}$ & $0 / 6$ & 0.0 & NA \\
\hline $1-2 m$ & $1 / 15$ & 6.7 & $\begin{array}{l}0.7- \\
27.2\end{array}$ & $0 / 7$ & 0.0 & NA & $1 / 8$ & 12.5 & $\begin{array}{l}1.4- \\
45.4\end{array}$ \\
\hline$>2 \mathrm{~m}$ & $1 / 9$ & 11.1 & $\begin{array}{l}1.2- \\
41.4\end{array}$ & $0 / 5$ & 0.0 & NA & $1 / 4$ & 25.0 & $\begin{array}{l}2.8- \\
71.6\end{array}$ \\
\hline
\end{tabular}

\section{SARS-CoV-2 RNA on surfaces}

We collected 252 surface samples, $182(72.2 \%)$ of which were from the hospital and 70 (27.8\%) from patients' homes. In total, 25/252 samples (9.9\%) from 15/27 collections (57.7\%) were PCR positive (Tables 4 and S5). Viable virus was not detected in any of the 212 cultured surface samples. There was no difference in the proportion of positive samples between the four surface groups $(p=0.646)$ or between home and hospital collections $(p=0.351)$. For a given positive collection, there was no significant difference between finding the virus from air or on surfaces $(p=0.344)$. 
PCR positive surface samples divided into four surface groups

\begin{tabular}{|c|c|c|c|c|c|c|c|c|c|}
\hline \multirow[t]{2}{*}{ Surface } & \multicolumn{3}{|l|}{ Total } & \multicolumn{3}{|c|}{ Hospital } & \multicolumn{3}{|c|}{ Home } \\
\hline & $\mathbf{N}$ & $\%$ & $95 \% \mathrm{Cl}$ & $\mathbf{N}$ & $\%$ & $95 \% \mathrm{Cl}$ & $\mathbf{N}$ & $\%$ & $95 \% \mathrm{Cl}$ \\
\hline \multicolumn{10}{|l|}{ High-touch surfaces } \\
\hline Bed remote & $1 / 2$ & 50.0 & $6.1-93.6$ & $1 / 2$ & 50.0 & $\begin{array}{l}6.1- \\
93.6\end{array}$ & NA & NA & NA \\
\hline $\begin{array}{l}\text { Other high-touch } \\
\text { surfaces }\end{array}$ & $4 / 11$ & 36.4 & $\begin{array}{l}13.7- \\
65.2\end{array}$ & $2 / 5$ & 40.0 & $\begin{array}{l}9.4- \\
79.1\end{array}$ & $2 / 6$ & 33.3 & $\begin{array}{l}7.7- \\
71.4\end{array}$ \\
\hline Cell phone & $3 / 26$ & 11.5 & $3.4-27.7$ & $1 / 19$ & 5.3 & $\begin{array}{l}0.6- \\
22.1\end{array}$ & $2 / 8$ & 25 & $\begin{array}{l}5.6- \\
59.2\end{array}$ \\
\hline Drinking glass & $2 / 18$ & 11.1 & $2.4-31.1$ & $0 / 11$ & 0.0 & NA & $2 / 7$ & 28.6 & $\begin{array}{l}6.5- \\
64.8\end{array}$ \\
\hline Computer & $1 / 12$ & 8.3 & $0.9-32.8$ & $0 / 2$ & 0.0 & NA & $1 / 10$ & 10.0 & $\begin{array}{l}1.1- \\
38.1\end{array}$ \\
\hline Door handle & $0 / 28$ & 0.0 & NA & $0 / 19$ & 0.0 & NA & $0 / 9$ & 0.0 & NA \\
\hline In total & $11 / 97$ & 11.3 & $6.2-18.8$ & $4 / 57$ & 7.0 & $\begin{array}{l}2.4- \\
15.8\end{array}$ & $7 / 40$ & 17.5 & $\begin{array}{l}8.2- \\
31.3\end{array}$ \\
\hline \multicolumn{10}{|l|}{ Low-touch surfaces } \\
\hline Hospital equipment & $2 / 9$ & 22.2 & $4.9-54.4$ & $2 / 9$ & 22.2 & $\begin{array}{l}4.9- \\
54.4\end{array}$ & NA & NA & NA \\
\hline Other low-touch surfaces & $1 / 6$ & 16.7 & $1.9-55.8$ & $1 / 4$ & 25.0 & $\begin{array}{l}2.8- \\
71.6\end{array}$ & $0 / 2$ & 0.0 & NA \\
\hline Floor & $4 / 22$ & 18.2 & $6.5-37.6$ & $4 / 16$ & 25.0 & $\begin{array}{l}9.1- \\
49.1\end{array}$ & $0 / 6$ & 0.0 & NA \\
\hline Table & $3 / 38$ & 7.9 & $2.3-19.6$ & $2 / 30$ & 6.7 & $\begin{array}{l}1.4- \\
19.7\end{array}$ & $1 / 8$ & 12.5 & $\begin{array}{l}1.4- \\
45.4\end{array}$ \\
\hline Bed rail & $1 / 19$ & 5.3 & $0.6-22.1$ & $1 / 19$ & 5.3 & $\begin{array}{l}0.6- \\
22.1\end{array}$ & NA & NA & NA \\
\hline Air vent & $0 / 2$ & 0.0 & NA & $0 / 1$ & 0.0 & NA & $0 / 1$ & 0.0 & NA \\
\hline In total & $11 / 96$ & 11.5 & $6.2-19$ & $10 / 79$ & 12.7 & $\begin{array}{l}6.7- \\
21.3\end{array}$ & $1 / 17$ & 5.9 & $\begin{array}{l}0.6- \\
24.4\end{array}$ \\
\hline \multicolumn{10}{|l|}{ Toilet surfaces } \\
\hline Toilet seat & $1 / 14$ & 7.1 & $0.8-28.8$ & $1 / 11$ & 9.1 & $\begin{array}{l}1.0- \\
35.3\end{array}$ & $0 / 3$ & 0.0 & NA \\
\hline Toilet flush button & $2 / 18$ & 11.1 & $0.6-23.2$ & $1 / 12$ & 8.3 & $\begin{array}{l}0.9- \\
32.5\end{array}$ & $1 / 6$ & 16.7 & $\begin{array}{l}1.9- \\
55.8\end{array}$ \\
\hline Tap & $0 / 11$ & 0.0 & NA & $0 / 7$ & 0.0 & NA & $0 / 4$ & 0.0 & NA \\
\hline Toilet bowl & $0 / 8$ & 0.0 & NA & $0 / 8$ & 0.0 & NA & NA & NA & NA \\
\hline In total & $3 / 51$ & 5.9 & $1.7-14.9$ & $2 / 38$ & 5.3 & $\begin{array}{l}1.1- \\
15.8\end{array}$ & $1 / 13$ & 7.7 & $\begin{array}{l}0.8- \\
30.7\end{array}$ \\
\hline
\end{tabular}




\begin{tabular}{|llllllllll|}
\hline Surface & \multicolumn{2}{l}{ Total } & \multicolumn{3}{c|}{ Hospital } & \multicolumn{5}{c|}{ Home } \\
\cline { 2 - 10 } & $\mathbf{N}$ & $\mathbf{9}$ & $\mathbf{9 5 \%} \mathbf{C l}$ & $\mathbf{N}$ & $\%$ & $\mathbf{9 5 \%} \mathbf{C l}$ & $\mathbf{N}$ & $\%$ & $\mathbf{9 5 \%} \mathbf{C l}$ \\
\hline Staff/PPE & $0 / 8$ & 0.0 & NA & $0 / 8$ & 0.0 & NA & NA & NA & NA \\
\hline Total & $25 / 252$ & 9.9 & $6.7-14.1$ & $16 / 182$ & 8.8 & $5.3-$ & $9 / 69$ & 12.9 & $6.6-$ \\
& & & & & & 13.6 & & & 22.1 \\
\hline
\end{tabular}

\section{Effects of patient factors on environmental contamination}

Positive air samples were found even when the index patient did not report any respiratory symptoms $(2 / 3,66.6 \%)$. However, there was a statistically significant connection between low oxygen saturation (SpO2) levels and SARS-CoV-2 RNA findings from surfaces, and a possible but nonsignificant connection between low SpO2 levels and RNA findings from the air (surface: $p=0.026$, air: $p=0.098$, Table S2). Toilet surfaces were PCR positive in 33.3\% (3/9) of cases when the index patient had GI symptoms and $0 \%$ of cases $(0 / 9)$ when the index patient did not report any GI symptoms ( $p=$ 0.229). Positive surface samples were detected more often when there were multiple COVID-19 patients in the ward/house during the sampling $(p=0.018)$. However, no statistically significant difference was detected for air collections ( $p=0.845$ ) (Fig.2a). Possible but statistically nonsignificant associations were observed between positive environmental samples and an earlier symptom day, as well as an older patient age (Fig.2b and 2c). No statistically significant connections were found between air and surface PCR results and laboratory results for index patients (Fig. S1).

\section{SARS-COV-2 in saliva}

Saliva samples were obtained from $26 / 31$ index patients and 10 other patients on the ward. In total, 22/26 of the index patient samples and 8/10 of the samples from other patients were PCR positive. Six of the PCR-positive samples taken between symptom days two and eleven were also positive in virus culture (five of which were index patients). Culturepositive samples had lower Ct values than culture-negative samples (Fig. S2). Additionally, patients P46, P50, and P51 provided daily follow-up saliva samples until symptom days 12,14 , and 17 , all of which (33/33) were PCR positive and seven of which were culture positive (Table S6).

RNA copy numbers in saliva samples varied between $1.65 \times 10^{3}$ and $5.13 \times 10^{7}$ copies $/ \mathrm{ml}$ (mean $3.55 \times 10^{6} \mathrm{copies} / \mathrm{ml}$ $\left(\right.$ SD $\left.\left.1.10 \times 10^{7}\right)\right)$. Age showed a trend of positive correlation with copy number, but it was not statistically significant (Spearman's rho $=0.339, p=0.106$, Fig. 3a). No statistically significant connections were found between copy number and the patient's laboratory results (Fig. S3), gender ( $p=0.312$ ), symptoms (Table S2, Fig. 3b), or time from the onset of symptoms (Spearman's rho $=0.004, p=0.987$, Fig. $3 c$ ). The copy number in saliva displayed an unsteady decline in two of the three patients who provided follow-up samples (Fig. 3d). The mean copy number in saliva of the index patients was $9.37 \times 10^{5}$ copies/ml (SD $\left.7.57 \times 10^{5}\right)$ in collections that had PCR-positive air samples and $7.74 \times 10^{6} \mathrm{copies} / \mathrm{ml}(\mathrm{SD}$ $\left.7.26 \times 10^{6}\right)$ in collections where all air samples were PCR negative $(p=0.536)$. The respective figures in relation to surface collections were $5.61 \times 10^{6}$ copies $/ \mathrm{ml}\left(\mathrm{SD} 1.52 \times 10^{7}\right)$ in positive collections and $1.54 \times 10^{5} \mathrm{copies} / \mathrm{ml}$ (SD 1.85 $\left.x 10^{5}\right)$ in negative collections $(p=0.291)$ (Fig. 3e).

\section{SARS-CoV-2 antibodies in serum samples}

Serum samples were obtained from 21 hospital-treated patients (13 index patients and six other patients on the ward) and four home-treated patients (two index patients and two other patients). In total, ten serum samples were positive for IgG or NAbs. Antibodies were detected at the earliest on symptom day 3 (P13, positive with two lgG tests, NAb titer 80). Of the antibody-positive patients, 9/10 were PCR positive from saliva and one (P16, symptom day 11, NAb titer 80 ) was 
also positive in viral culture. The index patients had NAbs against SARS-CoV-2 in five of the collections, and in four of these, PCR-positive environmental samples were detected (active air samples in one (P49, NAb titer >640), deposition air samples in two (P41 and P43, NAb titers 40 and 10), and surface samples in two (P13 and P43, NAb titers 80 and 10)).

\section{Environmental contamination and virus strain}

The virus variant was determined in seven index patients during 2021, five of whom were infected with alpha variant, one with an undetermined variant of concern $(\mathrm{VoC})$, and one with a non-VoC strain. The remaining cases were considered as non-VoC, as no VoC strains had yet been detected in Finland at the time of the collection. The mean RNA copy number in saliva was $1.12 \times 10^{7}$ (range $1.69 \times 10^{3}$ to $5.13 \times 10^{7}$, SD $2.25 \times 10^{7}$ ) in patients with a VoC strain and $1.71 \times 10^{6}$ (range $1.65 \times 10^{3}$ to $2.04 \times 10^{7}$, SD $4.89 \times 10^{6}$ ) in patients with a non-VoC strain $(\mathrm{p}=0.649)$. Altogether, $80 \%$ $(4 / 5)$ of collections had positive surface samples when the index patient had a VoC strain and $52.6 \%(10 / 19)$ when the index patient had a non-VoC strain $(p=0.358)$. The respective results for the air collections were $50 \%(3 / 6)$ with a VoC strain and $42.9 \%(9 / 21)$ with a non-VoC strain $(p=1.000)$.

\section{Transmission of COVID-19 to family members}

The spread of COVID-19 within the family was examined by collecting saliva samples from family members of the five home-treated patients and analyzing PCR results and SARS-CoV-2 antibody levels. In two families that used protective measures, including respiratory protection (surgical mask or respirator) and intensified cleaning, no further infections were detected. However, in three families that did not apply any protective measures or used only intensified cleaning, secondary infections were observed (see supplementary material for details).

\section{Discussion}

This study detected SARS-CoV-2 RNA from air in particle size ranges of 0.65-4.7 $\mu \mathrm{m},>7 \mu \mathrm{m},>10 \mu \mathrm{m}$, and $<100 \mu \mathrm{m}$ in diameter, extending previous findings of SARS-CoV-2 RNA in particles of $0.25-1.0 \mu \mathrm{m}, 1-4 \mu \mathrm{m}$, and $>4 \mu \mathrm{m}$ in size ${ }^{12,14}$. Our findings support discoveries that normal respiratory activities generate infective particles in the absence of aerosolgenerating procedures ${ }^{2,6,25}$. Most $(83 \%, 15 / 18)$ of our positive samples were in particles smaller than $4.7 \mu \mathrm{m}$, which strengthens the recent finding that at least $85 \%$ of the viral load is emitted in aerosols smaller than $5 \mu \mathrm{m}^{6}$.

SARS-CoV-2 was detected from air with a minimum collection period of 10 min (Andersen's impactor) and a minimum air volume of $72 \mathrm{I}$ (Button sampler). With an average respiratory rate of 14/min and volume of $0.5 \mathrm{I} / \mathrm{breath}$, this would mean exposure times of $40 \mathrm{~min}$ (Andersen) and $10 \mathrm{~min}$ (Button) for the examined virus variants (alpha and undetermined VoC (Andersen), as well as non-VoC (Button)). However, our results from respiratory activities demonstrated that $0.5-2$ min of activity did not produce enough virus to be detected with PCR, even from a close distance of $10 \mathrm{~cm}$. Current safety guidelines use 15 min exposure time regarding contact tracing ${ }^{26}$. Our results raise concern that shorter exposure time should be considered, at least for close contacts. Also, current virus variants such as the delta variant may further lower the exposure time needed for infection, as the estimated viral load in the presence of the delta variant is over 1000 times higher than the initial strain 27.

Multiple positive air samples were collected from a large $\left(655.25 \mathrm{~m}^{3}\right)$ mechanically ventilated hospital hall (Figure 1), even when there were only two patients. Overall, larger spaces are considered safer than small ones due to the larger air volume per person ${ }^{28}$. However, it seems that also larger indoor spaces may form a risk environment if occupied by an infected person for a prolonged time period as observed also in previous studies ${ }^{29-31}$. Higher viral loads have been associated with an increased probability of viral transmission ${ }^{32}$. We also found a higher number of patients in the room to be associated with higher numbers of positive surface samples. 
Toilet surface samples were positive only when the index patient reported GI symptoms. Infectious SARS-CoV-2 has been recovered from urine and stool samples ${ }^{33}$, and flushing of the toilet and vomiting can generate aerosols, which will later deposit on the surfaces ${ }^{34,35}$. This risk should be noted and toilets should not be shared with non-COVID patients. Other more frequently PCR-positive surfaces included highly-touched personal items, hospital equipment, and the floor, which is in line with previous findings ${ }^{13,14,21}$. Even though RNA may persist on surfaces for some time, RNA findings most likely result from contamination on the same day due to daily cleaning.

The relative importance of different infection routes remains somewhat unclear, although a recent animal study indicates that aerosol inoculation is a more efficient route and causes more severe pathology and higher viral loads ${ }^{36}$. The recent evidence estimates surface transmission to be likely rare, generally less than 1 in 10000 , and the disease manifestation milder ${ }^{37}$. In this study, families that took protective measures (including isolation of the infected family member) and respiratory protection (surgical masks or FFP2 respirators) were able to prevent further infections even when PCR-positive samples were collected from both surfaces and air. However, in a household where all surfaces were cleaned many times a day but no respiratory protection was used, all family members became infected. This supports the importance of air hygiene and also encourages control of infection spread in homes. Infection control is even more important with VoC strains that feature a higher rate of household transmission ${ }^{38}$.

To better understand the infectivity and state of the infection compared to the environmental findings, we collected saliva and serum samples from studied patients. SARS-CoV-2 was cultured from patients' saliva during symptom days $2-11$. In contradiction to previous finding $s^{39}$, no correlation emerged between days from the onset of symptoms and the RNA copy number $(p=0.987)$, which might partly be explained by our small sample size. SARS-CoV-2 RNA was detected in the saliva of patients who had already formed IgG and NAbs, which alines with previous findings of prolonged RTPCR-positivity ${ }^{40-42}$. In addition, saliva of P16 on symptom day 11 was still positive in virus culture, even though the patient had NAbs. Moreover, we obtained positive air and surface samples when the index patient had a positive IgG result and NAbs, which agrees with the findings of Lei et $\mathrm{al}^{43}$. This contradicts the suggestion that NAbs solely could be a reliable marker for non-infectivity ${ }^{40}$, but on the other hand, supports the finding that vaccinated individuals have caused secondary transmission ${ }^{44}$.

The effect of age on the generation of aerosols and thus the spread of SARS-CoV-2 has also been speculated ${ }^{45}$. We observed a strong trend for an older age being associated with a higher viral load and a larger number of positive surface samples, but confirming this would require further studies with a larger sample size. Possible reasons for the relationship between age and infectivity include reduced saliva production, differences in mucus viscosity and salivary immunoglobulins ${ }^{46}$, increased expression of the ACE2 receptors needed for cell entry of SARS-CoV- $2^{47}$, thinning of the epithelium $^{48}$, and impairment of the immune response with age ${ }^{49}$.

This study combined a large number of environmental samples and detailed patient data to more comprehensively understand environmental contamination and the effect of patient-dependent factors. The patient material was representative regarding symptoms and laboratory results for COVID-1950. In addition to the hospital environment, we collected samples from homes where patient symptoms are generally less severe, the time from the onset of symptoms is shorter, and air conditioning is different from that of a hospital.

Our study also has some limitations. We only conducted environmental sampling at a single time point. In the future, a longitudinal examination could enable more accurate examination of the effects of the course of disease for environmental contamination. In addition, we only measured the IgG and NAb response, but viral secretion from mucus membranes can continue if the $\lg A$ response is weak ${ }^{51}$. The $\lg A$ immune response should thus be examined further in upcoming studies. The qPCR results might include some uncertainty due to the differences in the texture and fluidity of 
saliva and should be considered as estimates. As many samples were collected from a large patient hall, it is possible that some observed viruses might have originated from other than the index patient. However, most of the surface samples were from patient-specific surfaces, and aerosols are known to concentrate near the source ${ }^{52}$, indicating that most of the positive samples are expected to be produced by the index patient. Particle size cutoffs in Andersen samplers might be slightly higher than estimated, as the amount of liquid used in the sampling was slightly smaller than recommended due to practical reasons. As seen also in earlier studies ${ }^{53}$, viral culture from environmental samples turned out to be difficult and insensitive. A significant loss of infective viruses in air sampling has been demonstrated in

previous research ${ }^{54-57}$. In the future, sampling methods and devices should be developed to better preserve the viability and infectivity, for example mimicking the humidity and airflow of the airways to avoid mechanical stress and utilizing direct collection onto the cells or culture medium to avoid losses during transport.

\section{Conclusions}

This study found SARS-CoV-2 RNA from air samples in wide range of different-sized particles during normal respiratory activity from both home and hospital environment. We observed positive air samples in collections corresponding to 10 minutes of normal respiration, although current restricted air sampling techniques may have caused some virus loss. We also detected SARS-CoV-2 RNA-positive air and surface samples after patients had developed antibodies, supporting recent findings of the possibility for secondary transmission from vaccinated people. These results highlight the need for appropriate infection control against airborne and surface transmission routes in both environments, even after antibody production has begun.

\section{Methods}

\section{Index patients and protocol for measurement safety}

Patients were voluntary participants with an RT-PCR-confirmed symptomatic COVID-19 infection between 1.7.202016.3.2021. None of the participants had been vaccinated. As infectivity has been observed to be highest in early disease, the patient with the fewest symptom days was selected as the index patient ${ }^{39}$, with the exception of collection 13 , where all the patients in the room had been symptomatic for over 10 days and the patient with the freshest positive PCR result (P26) was selected (Table S1). In one case, the index patient was the same in two collections, and in two other collections, two index patients were included. All research personnel conducting the sampling followed aerosol safety protocols and precautions and no infections were detected. All procedures that involved human participants, including environmental sampling, were conducted in accordance with the ethical standards of the institutional or national research committee and the 1964 Declaration of Helsinki and its later amendments or comparable ethical standards. The Ethics Committee of Helsinki University Hospital approved the study protocol (HUS/1701/2020). All respondents provided written informed consent prior to their participation.

\section{Measurement environment}

In total, 31 collections were performed, 24 of them on the cohort COVID-19 ward at the HUS Surgical Hospital, Helsinki, Finland. Of these, 22 were carried out on a relatively large ward with a completely open patient room area $\left(146.4 \mathrm{~m}^{2}\right.$, height $4.5 \mathrm{~m}$, total air volume $655.25 \mathrm{~m}^{3}$, and supply air of $421 \mathrm{l} / \mathrm{s}, 1.67$ air changes per hour (ACH)), and a maximum of 13 confirmed SARS-CoV-2 patients at a time. One collection was performed in the intensive care unit (ICU) (operating room mechanical ventilation, $>30 \mathrm{ACH}$ ) and one in a single patient room (mechanical ventilation, $1.67 \mathrm{ACH}$ ). The layout of the rooms is illustrated in Figure 1. The infection prevention and control protocols on the COVID ward included hand hygiene, universal masking for staff (FFP2/3 for ICU and surgical masks for the COVID ward), guidance on social distancing $(2 \mathrm{~m})$, and personal protecting equipment (PPE) following droplet precautions. The room was cleaned twice a 
day. Additionally, seven collections were performed in patients' homes in normal rooms where the patients spent time during illness. The measured rooms were circa $15-30 \mathrm{~m}^{2}$ in area with a normal room height of $2.5 \mathrm{~m}$ and circa $0.5 \mathrm{ACH}$. Cell lines

Vero E6 cells (VE6) and their TMPRSS2-expressing clone VE6-TMPRSS2-10 (VE6T) ${ }^{58}$ were grown as previously described $^{59}$. To inhibit fungal growth, $0.205 \mu \mathrm{g} / \mathrm{ml}$ of amphotericin B (Fungizone, Thermo Scientific) was added to the medium of the cells that were taken to the hospital for aerosol collections.

\section{Sampling protocols for air sampling}

Seven different air collection methods were used. Details of the collections and samples are presented in Table S3. A Dekati PM10 cascade impactor (20 I/min air flow) with three stages $(>10,>2.5$, and $>1 \mu \mathrm{m})$, intended to ascertain the particle distribution according to aerodynamic size (PM10, PM2.5, PM1, and a backup filter for particles $<1 \mu \mathrm{m}$ ), was used in eleven collections. The impaction stages of PM10, PM2.5, and PM1 were fitted with 25-mm-diameter cellulose acetate membrane filters (CA filter, GE Healthcare Life Sciences) and the backup plate with a 40-mm CA filter. The collector was placed within 1-2 $\mathrm{m}$ from the patient and particles were collected for 2-4 hours. After sampling, filters were immediately placed in $2 \mathrm{ml}$ (25-mm filter) or $3 \mathrm{ml}$ (40-mm filter) of minimal essential Eagle's medium (MEM, SigmaAldrich).

The BioSpot 300p bioaerosol sampler prototype (Aerosol Devices Inc.) has a flow rate of $8 \mathrm{I} / \mathrm{min}$ and a mechanism that allows water to condense on aerosol particles from as small as 5-10 nm to $20 \mu \mathrm{m}$ in diameter and minimize the stress when the sample is impacted onto the surface with the collection medium. To increase the sample collection rate, the biosampler is equipped with eight wicking tubes fitted with three nozzle jets to secure gentle transfer of the sample. This sampler was used in 8 collections for 1.5-4 hours within a distance of 1-2.5 $\mathrm{m}$ from the patient and the sample was collected in 1-2 $\mathrm{ml}$ of MEM.

As a more portable solution for personal area air sampling, a standard 25-mm gelatin (Sartorius Stedim Biotech) or mixed cellulose ester (MCE) filter equipped in the Button sampler with a Gilian 5000 air sampling pump, 4 I/min air flow, and a porous curved surface inlet was used in 9 collections. The Button sampler collects particles smaller than 100 $\mu \mathrm{m}^{60}$. The stability of SARS-COV-2 on two filter materials was compared under laboratory conditions to select the more optimal filter type and to optimize the collection time (details in supplementary material). Samples were collected for 10-30 min from patient's breathing area. Depending on the health status, a conversation was prompted to increase the output of aerosols. The collection filter was removed into $3 \mathrm{ml}$ of MEM immediately after collection ended.

Three Andersen cascade impactors (400 W pump and $28.3 \mathrm{l} / \mathrm{min}$ flow rate) were used simultaneously in six collections. The impactors consist of six stages with size cut points of: 1) >7 $\mu \mathrm{m}, 2)$ 4.7-7.0 $\mu \mathrm{m}, 3) 3.3-4.7 \mu \mathrm{m}, 4) 2.1-3.3 \mu \mathrm{m}, 5)$ 1.1-2.1 $\mu \mathrm{m}$, and 6) 0.65-1.1 $\mu \mathrm{m}$. To ensure the correct volume flow rate, each Andersen impactor was fitted with a TSI flow meter. Samples were collected using Petri dishes (94/16 MM) with $15 \mathrm{ml}$ of cell medium for 10, 20, and $30 \mathrm{~min}$. The medium was transferred onto VE6T cells grown on 100/20 MM cell culture dishes either immediately after collection in the hospital (collections $24,25,27$, and 29 ) or later in the laboratory (collection 31 ).

To evaluate the real-time particle number concentration during the hospital collections and to gather additional air samples, a Dekati eFilter was used in two collections. The eFilter monitors changes in real-time particle concentration by utilizing a small diffusion charger powered by an inner chargeable battery. The charge changes were automatically translated into a signal, which was recorded on a data card. When postprocessing the data, the raw charge signal was further converted to represent particle number concentrations using a conversion factor $\left(411 \mathrm{~cm}^{\wedge}-3 \mathrm{fA} \mathrm{A}^{\wedge}-1\right)$ provided by the manufacturer. A count median diameter (CMD) of $60 \mathrm{~nm}$ and a geometric standard deviation (GSD) of 1.5 were assumed $^{61,62}$. In addition, the eFilter simultaneously collected samples on a 47-mm gelatin filter using an external pump. 
After sample collection, the gelatin filter was transferred into $6 \mathrm{ml}$ of MEM. The eFilter was fitted with the same EPAdesigned inlets as the Andersen cascade impactors. The particle size cut point of the inlets was approximately $12 \mu \mathrm{m}$, with an air volume flow rate of $28.3 \mathrm{l} / \mathrm{min}$. The duration of sample collection was 30 minutes at a similar distance from the patient as with the Andersen's cascade impactors.

Passive air samples were collected either directly on VE6 cells (2 collections) or VE6T cells ( 9 collections) grown on 100/20 MM (collection 22) or 35/10 MM (other collections) cell culture dishes or on empty 35/10 MM Petri dishes containing $1 \mathrm{ml}$ of growth medium (10 collections). Open dishes were positioned at different proximities from the patient for 30-60 min, and the patient was encouraged to perform an aerosol-producing activity such as talking. The ability of SARS-CoV-2 to infect cells at room temperature was confirmed, and major differences in the culture sensitivity of these two collection methods were excluded under laboratory conditions (see supplementary methods for details).

Living cells were transported to the laboratory in a warm environment with heat accumulators warmed to $37^{\circ} \mathrm{C}$. One plate was used as a negative control to ensure that the cells survived the transport. Other samples were transported with cold accumulators and handled during the same or next day.

\section{Sampling protocols for surface sampling}

Altogether, 252 surface samples in 26 collections for PCR testing were taken from surfaces in possible direct or indirect contact with the patient (Supplementary Table 3) with pre-wetted Dacron swabs (Copan, 25 collections), a nitrile glove (1 collection), gauze (1 collection), or by pipetting the sampling liquid up and down on the surface a few times and transferring it into a sampling tube (3 collections). Swabs were placed into $1 \mathrm{ml}$ of PBS. In 22 collections (212 samples), an additional sample was taken for virus culture, which was placed in $250 \mu \mathrm{l}$ or $1 \mathrm{ml}$ of MEM. Samples for PCR and culturing were taken immediately next to each other. Surfaces were divided into four surface groups (high-touch surfaces, low-touch surfaces, toilet surfaces, and other surfaces) for statistical analyses.

\section{Other sampling protocols}

Saliva samples were taken from 26 index patients either with a Dacron swab (collections 5-9) or by spitting into a Falcon tube (from collection 10 onwards). Ten additional saliva samples were collected from other patients from the ward in four collections and from seven healthy family members of home-treated patients. If possible, patients were asked to rinse their mouth before sampling. In collection 23 , the index patient and a healthy family member also took follow-up saliva samples until 12 days from the start of the patient's symptoms. In collection 26, follow-up saliva samples were taken from patients until days 14-17 from the start of symptoms.

Nasopharyngeal samples from consenting patients were taken and sent to HUSLAB for a fresh diagnostic PCR ${ }^{63,64}$. Serum samples from consenting patients were taken within a day from sampling and tested for SARS-CoV-2 IgG antibodies with two different tests ${ }^{65}$. Serum samples (dilutions 1:10 to 1:640) were studied with the microneutralization assay $^{66}$. Blood lymphocyte and eosinophil counts, and plasma CRP from consenting patients were measured within a day of sampling, and plasma ferritin, ALP, ALT, D-dimer, and fibrinogen levels within three days. The respiration rate and Sp02 levels were measured during the same day (Table S1).

Since the first cases caused by variants of concern (VoC) were detected in Finland at the end of December 2020, they were determined from all patients as a part of routine diagnostics. This information was used to compare the results between VoC strains (mainly alpha in Finland) and non-VoC strains. Virus strains of collections 1-22 (P1-P45) were considered as non-VoC, as they were collected before the first cases were reported in Finland.

\section{RNA extraction and PCR protocols for air, saliva, and culture medium samples}

Page $14 / 24$ 
Trizol (Invitrogen) was used to extract RNA from all saliva samples and from air and culture medium samples of collections 1-23 according to the manufacturers' instructions. A 200- $\mu$ l sample was added to $800 \mu l$ of Trizol reagent and a resuspension volume of $50 \mu \mathrm{l}$ was used. RNA was extracted from air and culture medium samples of collections 24 onwards with a QIAcube HT system and QIAamp 96 Virus QIAcube HT kit (QIAgen) using off-board lysis.

All samples were tested with two different RT-PCRs, N Charité67 and N1 US CDC ${ }^{68}$, using TaqMan Fast Virus 1-Step Master Mix (ThermoFisher), a $20-\mu \mathrm{l}$ reaction volume, and fast cycling mode (annealing temperatures $55^{\circ} \mathrm{C}$ (N1 US CDC) and $58^{\circ} \mathrm{C}(\mathrm{N}$ Charité)). The primer and probe concentrations of $\mathrm{N}$ Charité were according to the original publication, and those of N1 US CDC were $500 \mathrm{nM}$ of both primers and $125 \mathrm{nM}$ of probe (Table S7). PCRs were performed using a Stratagene Mx3005P instrument (Agilent Technologies) with a Ct cut-off value of 0.04 . The results were considered positive if both PCRs were positive with a Ct value under 40 or if one PCR was positive with a Ct value under 38 . Samples with Ct values over 38 in one PCR and no Ct with the other one were treated as negative, even though the possibility of them being very weak positives could not be excluded. RNA extracted from the Fin/20 strain ${ }^{66}$ culture was used as a positive control and nuclease-free water as a negative control.

The N gene transcript for qPCR was prepared as follows: the target region (352-712, $360 \mathrm{bp}$ ) was amplified from SARS2 RNA, Wuhan strain, and cloned into pGEM-T cloning vector (Promega, Madison, USA) under control of the SP6 promoter. The presence of the insert was verified by sequencing and restriction enzyme analysis. After linearization of the plasmid by digestion with Ascl (Thermo Fisher Scientific, USA), RNA was generated using the RiboMAX ${ }^{\text {TM }}$ Large Scale RNA production system with SP6 polymerase (Promega, Madison, USA) according to the manufacturer's instructions. The transcribed RNA was then treated with DNAse I and purified with the RNeasy Mini Kit (QIAGEN, Hilden, Germany). Finally, RNA was quantified by spectrophotometry and the RNA copy number was calculated based on its concentration, length, and molecular weight. QPCR was performed with N Charité PCR by including a dilution series from 10 to $10^{9}$ copies/reaction in triplicate.

\section{RNA extraction and PCR protocols for surface samples}

RNA was extracted with the NucliSENS miniMAG kit (Biomerieux). Process control virus (mengovirus) was added to at least half of the samples. Tubes containing PBS and swabs were mixed by vortexing and swabs were moved to $1 \mathrm{ml}$ of high pH tris-glycine-beef extract buffer (TGBE, pH 9.5). The tubes were vortexed again and agitated at 250 rpm for 5 minutes in an orbital shaker (IKAKS 2060 basic, Patterson Scientific, UK), and the swabs were moved into a tube with 4 $\mathrm{ml}$ of lysis buffer, vortexed and agitated at $250 \mathrm{rpm}$ for 10 minutes. PBS, TGBE, and lysis buffer were then combined, vortexed, and incubated for 10 minutes. PBS without process control virus was included as a negative control and PBS with process control virus as a positive control. The rest of the extraction was carried out according to the NucliSENS miniMAG kit instructions. The samples were further treated with the OneStep PCR Inhibitor Removal Kit (Zymo Research, CA, USA) according to the manufacturer's instructions.

Samples were tested for SARS-CoV-2 with modified versions of N Charité ${ }^{67}$ and N1 US CDC PCRs ${ }^{68}$ and for process control virus ${ }^{69}$. The RT-PCR was carried out using a QuantiTect Probe RT-PCR kit (Qiagen, USA). Reaction mixes included $10 \mu$ l of $2 X$ QuantiTect Probe RT-PCR Master Mix, $0.2 \mu$ l of QuantiTect RT mix, $0.6 \mu \mathrm{M}$ of forward and $0.8 \mu \mathrm{M}$ of reverse primer, $0.2 \mu \mathrm{M}$ of probe for N Charité PCR primers, and $5 \mu \mathrm{l}$ of RNA template, and the volume was adjusted to $20 \mu \mathrm{l}$ with water. For US CDC PCR, final concentrations of $0.5 \mu \mathrm{M}$ for both primers and $0.2 \mu \mathrm{M}$ for the probe were used. For mengovirus PCR, $1 \mu \mathrm{M}$ of both primers and $0.2 \mu \mathrm{M}$ of probe were used. N Charite and N1 US CDC runs included one $10^{-4}$ dilution of SARS-CoV-2 RNA extracted from cell-grown virus as a standard positive control and one or two blanks as a standard negative control, and the reactions were performed in duplicate whenever the sample amount was sufficient. A Rotor Gene 3000 (Qiagen) real-time PCR cycler was used. The cycling conditions were reverse transcription for $30 \mathrm{~min}$ at $53^{\circ} \mathrm{C}$, a denaturation step at $95^{\circ} \mathrm{C}$ for $15 \mathrm{~min}$, followed by 45 cycles of amplification/denaturation at $95^{\circ} \mathrm{C}$ for $15 \mathrm{~s}$,

Page 15/24 
annealing at $58^{\circ} \mathrm{C}$ for $45 \mathrm{~s}$, and extension at $72^{\circ} \mathrm{C}$ for $45 \mathrm{~s}$. The results were analyzed with the thermocycler software Rotor-Gene 6.0.31 (Qiagen, USA) using similar criteria as with other samples described above.

\section{Culturing protocols}

Samples were initially cultured in VE6 cells (collections 1-18), which were changed to VE6T cells after reports of these being more sensitive (collections 19-31) 61 . Air samples that were collected directly on cells were cultured as such, and the rest of the air and surface samples and $75 \mu \mathrm{l}$ of saliva were used for culturing in 6-well plates. Medium was added to the final volume of $3 \mathrm{ml}$ (saliva) or $2 \mathrm{ml}$ (other samples). E-filter samples were cultured in two wells (3 $\mathrm{ml} /$ well). Samples were cultured at $37^{\circ} \mathrm{C}$ for $10-14$ days and checked for cytopathic effect (CPE). A $200-\mu$ sample of culture medium was taken from those samples that had unclear results based on microscopic observation or possible CPE and tested with $\mathrm{N}$ Charité PCR. Culturing was considered positive if CPE was detected and the Ct value of PCR performed from the culture media was under 20. If Ct value was higher, it was judged to be caused by original (possibly noninfectious) virus in the sample instead of virus growth. All virus culturing was performed in a BSL3 laboratory. Optimization of the culturing protocols is described in more detail in the supplementary material.

\section{Statistical tests}

Statistical tests were carried out with SPSS IBM Statistics version 27. When comparing means between two independent groups, data were first tested for normality with the Shapiro-Wilk test before testing them either with the independentsamples t-test or a non-parametric test (independent-samples Mann-Whitney U-test for two groups and independentsamples Kruskal-Wallis test for more than two groups). For categorical data, the Fisher-Freeman-Halton exact test was used. Air and surface results of collections were compared with McNemar's test. Spearman's rank correlation coefficient was used for correlation testing. Mean values and standard deviations (normally distributed data), medians and interquartile ranges (non-normally distributed data), or percentages (categorical data) of compared subgroups, test statistics, p-values, and effect sizes (Cohen's $d$ for the t-test and $\mathrm{z} / \sqrt{N}$ for the Mann-Whitney U-test) are reported in Table S2. P-values below 0.05 were considered statistically significant. Air or surface collections were considered positive if at least one of the samples from the collection was PCR positive. Individual data points that were added to the boxplot figures were jittered in all dimensions using a uniform distribution.

\section{Abbreviations}

Severe acute respiratory syndrome coronavirus 2 (SARS-CoV-2), Helsinki University Hospital (HUS), reverse transcription polymerase chain reaction (RT-PCR), quantitative real-time polymerase chain reaction (qPCR), neutralizing antibodies (NAbs), intensive care unit (ICU), C-reactive protein (CRP), gastrointestinal (GI), alkaline phosphatase (ALP), alanine aminotransferase (ALT), Andersen six-stage cascade impactor (Andersen), BioSpot 300p bioaerosol sampler (BioSpot), Button sampler (Button), Dekati PM10 cascade impactor (Dekati), Dekati eFilter (eFilter), variant of concern (VoC), air changes per hour $(\mathrm{ACH})$, oxygen saturation ( $\mathrm{SpO} 2)$

\section{Declarations}

\section{Data Availability}

All data are included in the article or its online supplementary material and are available from the corresponding author upon request.

\section{Acknowledgements}


We thank Esa Pohjalainen for assistance in the lab, Emma Klemetti for the illustrations of Figure 1 and Dekati Ltd for lending measurement equipments.

This study was financially supported by Business Finland Corona Co-Creation funding 40988/31/2020, the Scientific Advisory Board for Defense (MATINE) grant number VN/627/2020-PLM-9 (materials and equipments), Academy of Finland funding number 309570 and Academy of Finland COVID-19 special funding number 335681, as well as Helsinki University Hospital research grant M7100COVID, Jalmari ja Rauha Ahokkaan Säätiö - grant and Jane and Aatos Erkko foundation.

\section{Author contributions}

L-M.O., J.V., A.P.H., V.V., K.A., I.K., Le.L., T.S., S.S., L.M, N.S.A., N.R., E.S, and S.L., designed the study and developed the methodology, L-M.O., J.V., V.V., K.A., S.S., N.S.A., A.D.P., N.R., J.K., and J.S collected the samples, J.V., V.V., K.A., I.K., A.D.P., L.M., and J.K., analyzed the samples, L-M.O. and J.V. analyzed and visualized the data, L-M.O. and J.V. wrote the original draft, all authors revised and edited the manuscript, T.S., N.S.A., L.M., and A.G. supervised the study, and L-M.O, A.-P.H., T.S., N.S.A, E.S., V-J.A., La.L, M.L., and A.G. were responsible for project administration, funding and recourses.

\section{Competing interests}

The authors declare no competing interests.

\section{References}

1. Macintyre, C. R. \& Ananda-Rajah, M. R. Scientific evidence supports aerosol transmission of SARS-COV-2. Antimicrobial Resistance and Infection Control, 9, 202 (2020).

2. Greenhalgh, T. et al. Ten scientific reasons in support of airborne transmission of SARS-CoV-2.Lancet (London, England)0, (2021)

3. Tang, J. W., Marr, L. C., Li, Y. \& Dancer, S. J. Covid-19 has redefined airborne transmission. BMJ, 373, n913 (2021).

4. Wang, C. C. et al. Airborne transmission of respiratory viruses.Science (80-.). 373, (2021)

5. Lewis, D. COVID-19 rarely spreads through surfaces. So why are we still deep cleaning? Nature vol. 590 26-28 (2021)

6. Coleman, K. K. et al. Viral Load of Severe Acute Respiratory Syndrome Coronavirus 2 (SARS-CoV-2) in Respiratory Aerosols Emitted by Patients With Coronavirus Disease 2019 (COVID-19) While Breathing, Talking, and Singing.Clin. Infect. Dis.(2021) doi:10.1093/CID/CIAB691.

7. Fears, A. C. et al. Persistence of Severe Acute Respiratory Syndrome Coronavirus 2 in Aerosol Suspensions. Emerg. Infect. Dis.26, (2020)

8. van Doremalen, N. et al. Aerosol and Surface Stability of SARS-CoV-2 as Compared with SARS-CoV-1.N. Engl. J. Med.(2020) doi:10.1056/nejmc2004973.

9. Lednicky, J. A. et al. Viable SARS-CoV-2 in the air of a hospital room with COVID-19 patients. Int. J. Infect. Dis, 100, 476-482 (2020).

10. Lednicky, J. A. et al. Isolation of SARS-CoV-2 from the air in a car driven by a COVID patient with mild illness. medRxiv 2021.01.12.21249603(2021) doi:10.1101/2021.01.12.21249603

11. Adenaiye, O. O. et al. Infectious SARS-CoV-2 in Exhaled Aerosols and Efficacy of Masks During Early Mild Infection.Clin. Infect. Dis.(2021) doi:10.1093/CID/CIAB797.

12. Liu, Y. et al. Aerodynamic analysis of SARS-CoV-2 in two Wuhan hospitals., 582, 557-560 (2020). 
13. Santarpia, J. L. et al. Aerosol and surface contamination of SARS-CoV-2 observed in quarantine and isolation care. Sci. Rep, 10, 12732 (2020).

14. Chia, P. Y. et al. Detection of air and surface contamination by SARS-CoV-2 in hospital rooms of infected patients. Nat. Commun, 11, 1-7 (2020).

15. Nissen, K. et al. Long-distance airborne dispersal of SARS-CoV-2 in COVID-19 wards. Sci. Rep, 10, 1-9 (2020).

16. Aboubakr, H. A., Sharafeldin, T. A. \& Goyal, S. M. Stability of SARS-CoV-2 and other coronaviruses in the environment and on common touch surfaces and the influence of climatic conditions: A review. Transboundary and Emerging Diseasesvol. 68 (2020)

17. Biryukov, J. et al. Increasing Temperature and Relative Humidity Accelerates Inactivation of SARS-CoV-2 on Surfaces. mSphere 5(2020)

18. Chin, A. W. H. et al. Stability of SARS-CoV-2 in different environmental conditions. The Lancet Microbe, 1, e10 (2020).

19. Virtanen, J., Aaltonen, K., Kivistö, I. \& Sironen, T. Survival of SARS-CoV-2 on Clothing Materials. Adv. Virol. 2021, (2021)

20. Firquet, S. et al. Survival of Enveloped and Non-Enveloped Viruses on Inanimate Surfaces. Microbes Environ, 30, 140 (2015).

21. Guo, Z. D. et al. Aerosol and Surface Distribution of Severe Acute Respiratory Syndrome Coronavirus 2 in Hospital Wards, Wuhan, China, 2020. Emerg. Infect. Dis, 26, 1586-1591 (2020).

22. Ayoub, H. H. et al. Age could be driving variable SARS-CoV-2 epidemic trajectories worldwide. PLoS One, 15, e0237959 (2020).

23. Goldstein, E., Lipsitch, M. \& Cevik, M. On the Effect of Age on the Transmission of SARS-CoV-2 in Households, Schools, and the Community. J. Infect. Dis, 223, 362-369 (2021).

24. Kim, Y. I. et al. Critical role of neutralizing antibody for SARS-CoV-2 reinfection and transmission. https://doi.org/10.1080/22221751. 2021.1872352 10, 152-160 (2021)

25. Klompas, M., Baker, M. \& Rhee, C. What Is an Aerosol-Generating Procedure? JAMA Surgery, 156, 113-114 (2021).

26. Public Health Guidance for Community-Related Exposure | CDC. https://www.cdc.gov/coronavirus/2019ncov/php/public-health-recommendations.html

27. Lu, J. et al. Viral infection and transmission in a large, well-traced outbreak caused by the SARS-CoV-2 Delta variant. (2021) doi:10.21203/RS.3.RS-738164/V1

28. Bazant, M. Z. \& Bush, J. W. M. A guideline to limit indoor airborne transmission of COVID-19. Proc. Natl. Acad. Sci. 118, (2021)

29. Katelaris, A. L. et al. Epidemiologic Evidence for Airborne Transmission of SARS-CoV-2 during Church Singing, Australia, 2020 - Volume 27, Number 6-June 2021 - Emerging Infectious Diseases journal - CDC. Emerg. Infect. Dis, 27, 1677-1680 (2021).

30. Cai, J. et al. Indirect Virus Transmission in Cluster of COVID-19 Cases, Wenzhou, China, 2020. Emerg. Infect. Dis. 26, $1343-1345$ (2020)

31. Brlek, A., Vidovič, Å., Vuzem, S., Turk, K. \& Simonović, Z. Possible indirect transmission of COVID-19 at a squash court, Slovenia, March 2020: case report.Epidemiol. Infect.148, (2020)

32. Marc, A. et al. Quantifying the relationship between SARS-CoV-2 viral load and infectiousness. Elife10, (2021)

33. Jones, D. et al. Shedding of SARS-CoV-2 in feces and urine and its potential role in person-to-person transmission and the environment-based spread of COVID-19.Sci. Total Environ.749, (2020) 
34. Schreck, J. H., Lashaki, M. J., Hashemi, J., Dhanak, M. \& Verma, S. Aerosol generation in public restrooms. Phys. Fluids, 33, 033320 (2021).

35. Makison Booth, C. \& Frost, G. Potential distribution of viable norovirus after simulated vomiting. J. Hosp. Infect, 102, 304-310 (2019).

36. Port, J. R. et al. SARS-CoV-2 disease severity and transmission efficiency is increased for airborne compared to fomite exposure in Syrian hamsters. Nat. Commun. 2021 121 12, 1-15 (2021)

37. Science Brief SARS-CoV-2 and Surface (Fomite) Transmission for Indoor Community Environments | CDC. https://www.cdc.gov/coronavirus/2019-ncov/more/science-and-research/surface-transmission.html

38. Buchan, S. A. et al. Increased Household Secondary Attacks Rates With Variant of Concern Severe Acute Respiratory Syndrome Coronavirus 2 Index Cases.Clin. Infect. Dis.(2021) doi:10.1093/CID/CIAB496.

39. Cevik, M. et al. SARS-CoV-2, SARS-CoV, and MERS-CoV viral load dynamics, duration of viral shedding, and infectiousness: a systematic review and meta-analysis. The Lancet Microbe, 2, e13-e22 (2021).

40. van Kampen, J. J. A. et al. Duration and key determinants of infectious virus shedding in hospitalized patients with coronavirus disease-2019 (COVID-19). Nat. Commun. 2021 121 12, 1-6 (2021)

41. Li, Y. et al. Clinical characteristics, cause analysis and infectivity of COVID-19 nucleic acid repositive patients: A literature review. J. Med. Virol, 93, 1288-1295 (2021).

42. Jaafar, R. et al. Correlation Between 3790 Quantitative Polymerase Chain Reaction-Positives Samples and Positive Cell Cultures, Including 1941 Severe Acute Respiratory Syndrome Coronavirus 2 Isolates. Clin. Infect. Dis, 72, e921e921 (2021).

43. Lei, H. et al. SARS-CoV-2 environmental contamination associated with persistently infected COVID-19 patients. Influenza Other Respi. Viruses, 14, 688-699 (2020).

44. Hetemäki, I. et al. An outbreak caused by the SARS-CoV-2 Delta variant (B.1.617.2) in a secondary care hospital in Finland, May 2021. Eurosurveillance, 26, 2100636 (2021).

45. Edwards, D. A. et al. Exhaled aerosol increases with COVID-19 infection, age, and obesity. Proc. Natl. Acad. Sci. 118(2021)

46. Xu, F., Laguna, L. \& Sarkar, A. Aging-related changes in quantity and quality of saliva: Where do we stand in our understanding? J. Texture Stud, 50, 27-35 (2019).

47. Baker, S. A., Kwok, S., Berry, G. J. \& Montine, T. J. Angiotensin-converting enzyme 2 (ACE2) expression increases with age in patients requiring mechanical ventilation. PLoS One, 16, e0247060 (2021).

48. Sivaraman, K., Chopra, A., Narayana, A. \& Radhakrishnan, R. A. A five-step risk management process for geriatric dental practice during SARS-CoV-2 pandemic., 38, 17-26 (2021).

49. Montecino-Rodriguez, E., Berent-Maoz, B. \& Dorshkind, K. Causes, consequences, and reversal of immune system aging. J. Clin. Invest, 123, 958 (2013).

50. Pourbagheri-Sigaroodi, A., Bashash, D., Fateh, F. \& Abolghasemi, H. Laboratory findings in COVID-19 diagnosis and prognosis. Clin. Chim. Acta, 510, 475 (2020).

51. Sterlin, D. et al. IgA dominates the early neutralizing antibody response to SARS-CoV-2. Sci. Transl. Med, 13, 2223 (2021).

52. Vuorinen, V. et al. Modelling aerosol transport and virus exposure with numerical simulations in relation to SARSCoV-2 transmission by inhalation indoors. Saf. Sci, 130, 104866 (2020).

53. Verreault, D., Moineau, S. \& Duchaine, C. Methods for Sampling of Airborne Viruses. Microbiol. Mol. Biol. Rev, 72, 413 (2008). 
54. Fabian, P., McDevitt, J. J., Houseman, E. A. \& Milton, D. K. Airborne influenza virus detection with four aerosol samplers using molecular and infectivity assays: considerations for a new infectious virus aerosol sampler., 19, 433 (2009).

55. Tseng, C. C. \& Li, C. S. Collection efficiencies of aerosol samplers for virus-containing aerosols. J. Aerosol Sci, 36, 593-607 (2005).

56. Turgeon, N., Toulouse, M. J., Martel, B., Moineau, S. \& Duchaine, C. Comparison of Five Bacteriophages as Models for Viral Aerosol Studies. Appl. Environ. Microbiol, 80, 4242 (2014).

57. Fedorenko, A., Grinberg, M., Orevi, T. \& Kashtan, N. Survival of the enveloped bacteriophage Phi6 (a surrogate for SARS-CoV-2) in evaporated saliva microdroplets deposited on glass surfaces. Sci. Reports 2020, 101 10, 1-10 (2020).

58. Rusanen, J. et al. A generic, scalable, and rapid time-resolved förster resonance energy transfer-based assay for antigen detection-sars-cov-2 as a proof of concept. MBio 12(2021)

59. Virtanen, J. et al. Kinetics of Neutralizing Antibodies of COVID-19 Patients Tested Using Clinical D614G, B.1.1.7, and B 1.351 Isolates in Microneutralization Assays. Viruses13, (2021)

60. Aizenberg, V., Grinshpun, S., Willeke, K., Smith, J. \& Baron, P. Performance characteristics of the button personal inhalable aerosol sampler. AlHAJ, 61, 398-404 (2000).

61. Riesenfeld, E. et al. Ultrafine Particle Concentrations in a Hospital. http://dx.doi.org/10.1080/08958378. 2000.11463201 12, 83-94 (2015)

62. Dekati Dekati® PM10 Impactor | DEKATI. 358, 1-4 (2010)

63. Mannonen, L. et al. Comparison of Two Commercial Platforms and a Laboratory-Developed Test for Detection of Severe Acute Respiratory Syndrome Coronavirus 2 (SARS-CoV-2) RNA. J. Mol. Diagnostics, 23, 407-416 (2021).

64. Kortela, E. et al. Real-life clinical sensitivity of SARS-CoV-2 RT-PCR test in symptomatic patients. PLoS One, 16, e0251661 (2021).

65. Jääskeläinen, A. J. et al. Performance of six SARS-CoV-2 immunoassays in comparison with microneutralisation. J. Clin. Virol, 129, 104512 (2020).

66. Haveri, A. et al. Serological and molecular findings during SARS-CoV-2 infection: the first case study in Finland, January to February 2020. Eurosurveillance, 25, 2000266 (2020).

67. Corman, V. M. et al. Detection of 2019 novel coronavirus (2019-nCoV) by real-time RT-PCR.Eurosurveillance25, (2020)

68. CDC 2019-Novel Coronavirus. -nCoV) Real-Time RT-PCR Diagnostic Panel For (Emergency Use Only Instructions for Use, 2019).

69. Pintó, R., Costafreda, M. \& Bosch, A. Risk assessment in shellfish-borne outbreaks of hepatitis A. Appl. Environ. Microbiol, 75, 7350-7355 (2009).

\section{Figures}


a.

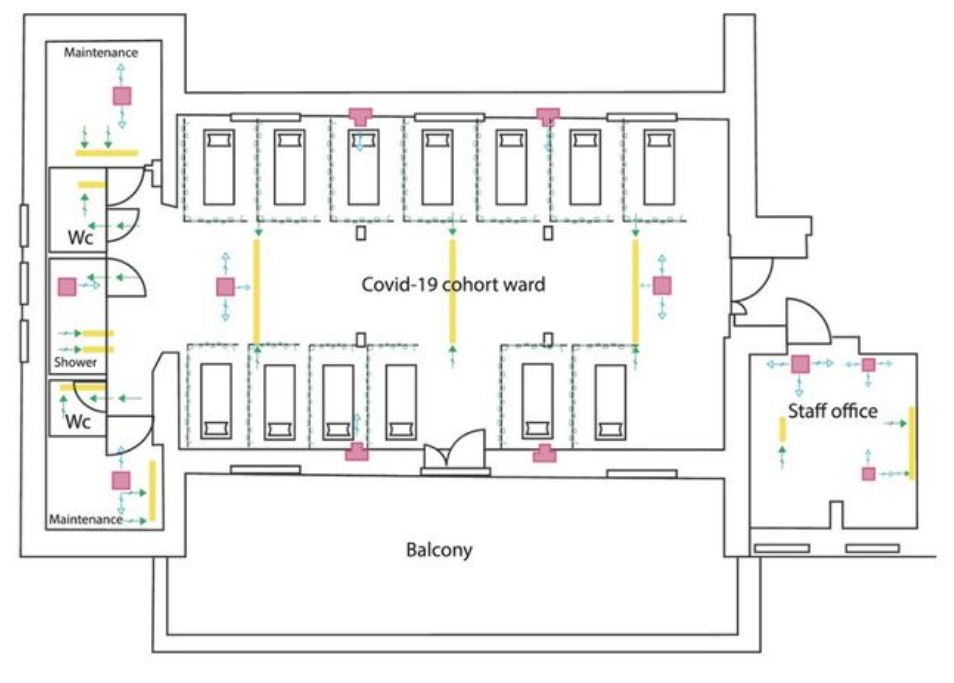

b.

Single room

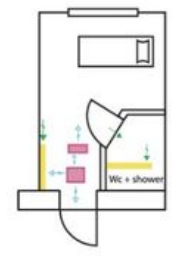

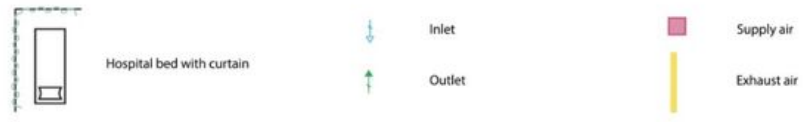

c.

1.

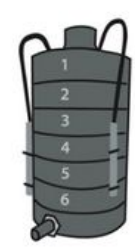

2.

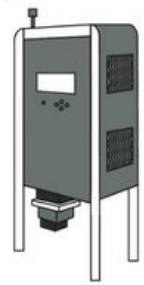

3.

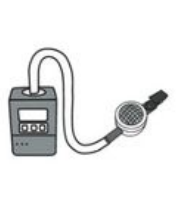

4.

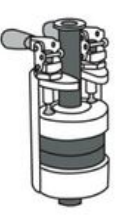

5.

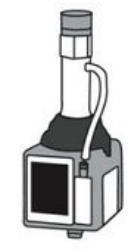

\begin{tabular}{|c|c|c|c|c|c|}
\hline $\begin{array}{l}\text { Distance from the } \\
\text { index patient }(m)\end{array}$ & $0.7 \mathrm{~m}$ & $1.5 \mathrm{~m}$ & $0.3 \mathrm{~m}$ & $1.4 \mathrm{~m}$ & $0.9 \mathrm{~m}$ \\
\hline $\begin{array}{l}\text { Height of the } \\
\text { inlet from the } \\
\text { floor }(m)\end{array}$ & c. $1.0 \mathrm{~m}$ & c. $1.2 \mathrm{~m}$ & c. $1.0 \mathrm{~m}$ & c. $1.5 \mathrm{~m}$ & c. $1.0 \mathrm{~m}$ \\
\hline
\end{tabular}

\section{Figure 1}

Sampling set up. a Layout of the COVID-19 cohort ward. b Layout of the single-patient room. c Locations of the sampling spots for the active air samplers around the patient (1: Andersen, 2: BioSpot, 3: Button, 4: Dekati, and 5: eFilter). 


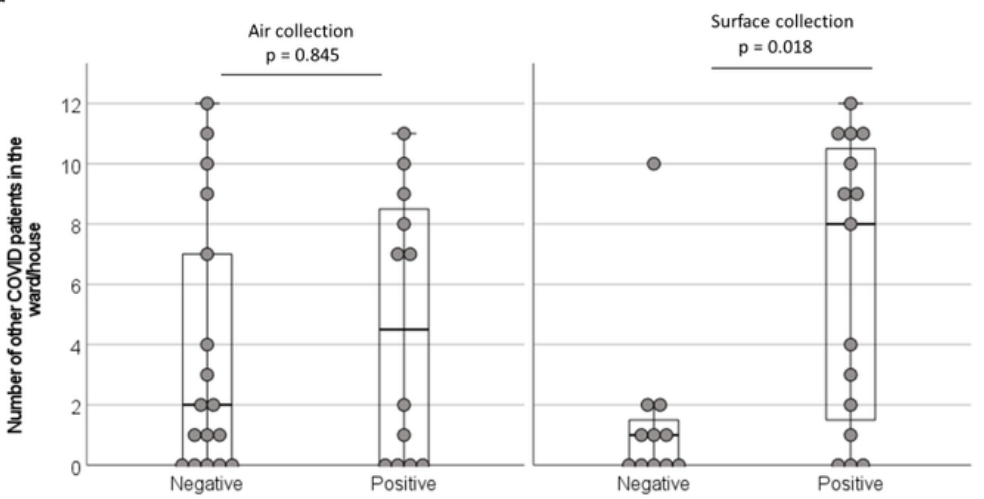

b

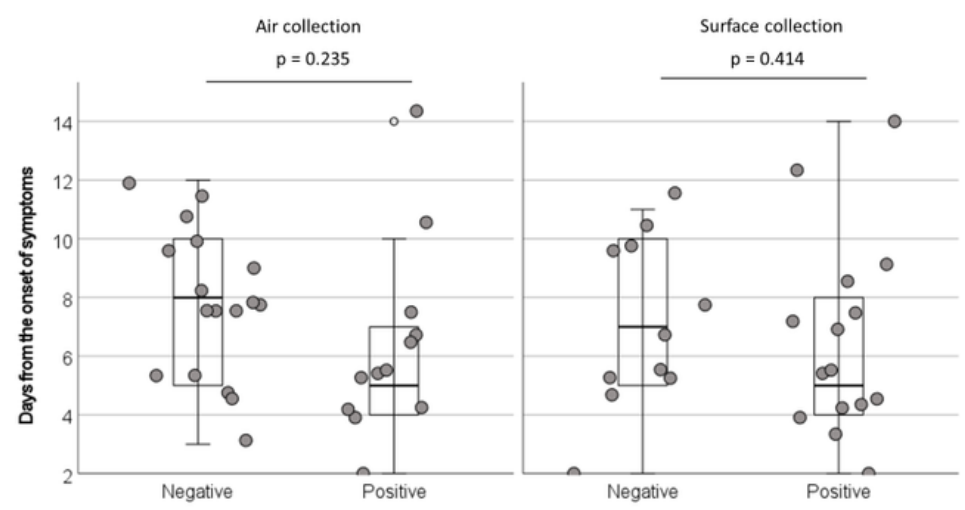

c

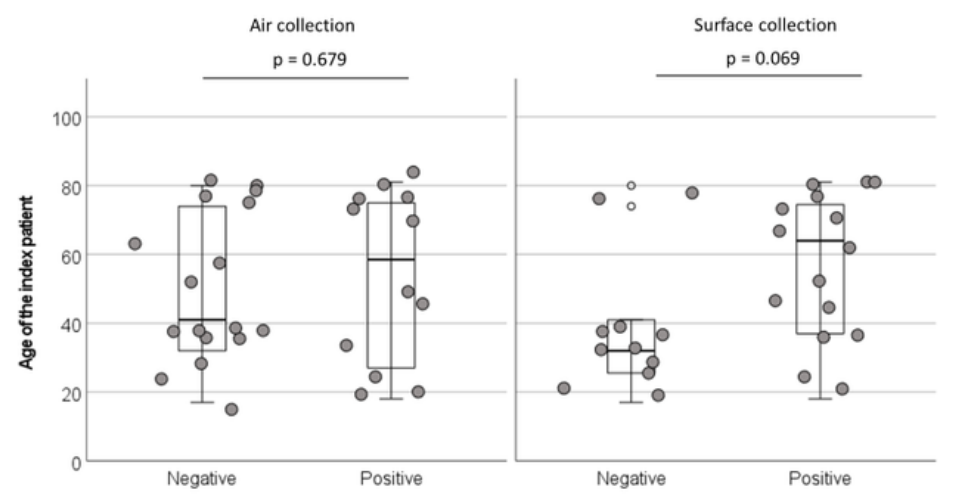

Figure 2

Connections between environmental contamination and patient characteristics. a Number of COVID patients in the ward/house. b Days from the onset of symptoms. c Age of the index patient. 

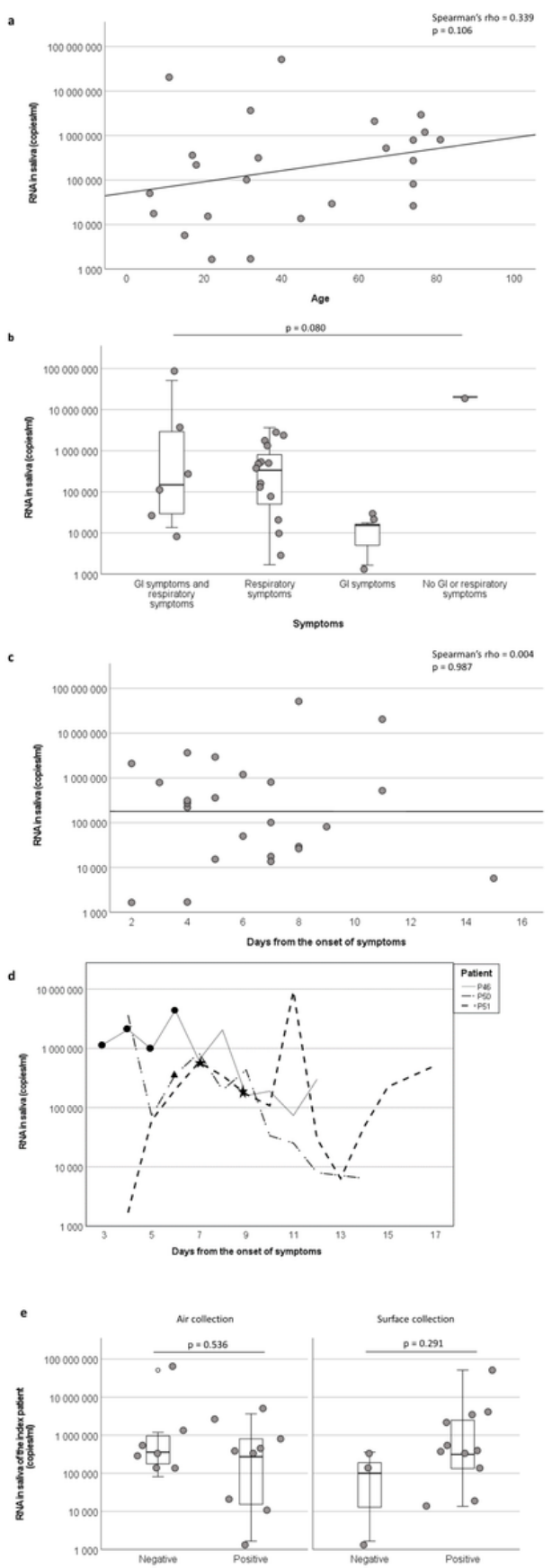

Figure 3

Comparisons of SARS-CoV-2 RNA copy number in saliva with other results and patient characteristics. a Correlation between copy number and age. b Copy number grouped by symptoms ( $\mathrm{GI}$ = gastrointestinal). c Correlation between copy number and time from the onset of symptoms. $d$ Changes in the copy numbers of three individual patients. Days when the virus culture was also positive are marked with dots (P46), triangles (P50), and stars (P51). e Copy number in saliva of the index patient grouped by PCR results from air and surface collection.

\section{Supplementary Files}

This is a list of supplementary files associated with this preprint. Click to download.

- 20211020SupplementarymaterialsforSARSCoV2airandsurfacecontaminationonaCOVID19wardandathome.docx 
- SupplementarytablesSARSCoV2airandsurfacecontaminationonaCOVID19wardandathomeOksanenVirtanenetal.xIsx 